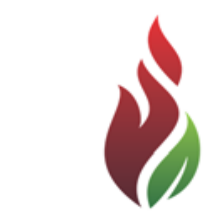

SUSTENERE

Publishing Corporation

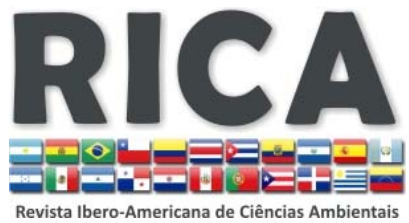

Journals Homepage:

www.sustenere.co/journals

\section{MUDANÇAS CLIMÁTICAS E OS DESAFIOS DO SETOR DOS RECURSOS HÍDRICOS EM CABO VERDE}

\section{RESUMO}

Segundo última publicação do Painel Intergovernamental sobre Mudanças Climáticas (IPCC, 2013), há $95 \%$ de certeza que a principal causa das atuais alterações do clima advém dos moldes de desenvolvimento económico adotados a partir da Revolução Industrial. Recursos Naturais que dependem da homeostase dos ciclos biogeoquímicos serão impactados e poderão colocar em causa os avanços socioeconómicos dos Países desenvolvidos e dos em desenvolvimento. O arquipélago de Cabo Verde localizado na costa da África Ocidental, inserido na área biogeográfica da Macaronésia, depende exclusivamente do regime pluviométrico para recarregar suas reservas de água tanto superficial quanto subterrânea. Diante de tal crise ambiental, faz-se necessário adotar estratégias incisa, pró ativa e deliberada para ultrapassar os desafios atuais e futuros do setor dos recursos hídricos no País. Neste âmbito, o presente trabalho tem como objetivo apresentar os impactos potenciais das mudanças climáticas e da variabilidade climática e os principais desafios para o setor dos recursos hídricos em Cabo Verde.

PALAVRAS-CHAVES: Mudanças Climáticas; Variabilidade Climática; Recursos Hídricos.

\section{CLIMATE CHANGE AND INDUSTRY CHALLENGES OF WATER RESOURCES IN CABO VERDE}

\section{ABSTRACT}

According to the last publication of the Intergovernmental Panel on Climate Change (IPCC, 2013), there is $95 \%$ certainty that the main cause of current climate change comes from economic development molds adopted since the Industrial Revolution. Natural resource -dependent homeostasis of biogeochemical cycles will be impacted and may jeopardize the socio-economic progress of developed and developing countries. The Cape Verde archipelago located off the coast of West Africa, located on the Macaronesian biogeographical area, depends solely on rainfall to recharge their water so shallow as underground. Faced with this environmental crisis, it is necessary to adopt incised, pro active and deliberate strategies to overcome current and future challenges of the water sector in this country. In this context, this paper aims to present the actual and potential impacts of changes climate and climate variability and main challenges for the sector of water resources in Cabo Verde.

KEYWORDS: Climate Change; Climate Variability; Water Resources.
Revista Ibero-Americana de

Ciências Ambientais, Aquidabã, v.5, n.1, Dez 2013, Jan, Fev, Mar, Abr, Mai 2014.

ISSN 2179-6858

SECTION: Articles

TOPIC: Mudanças Climáticas Globais

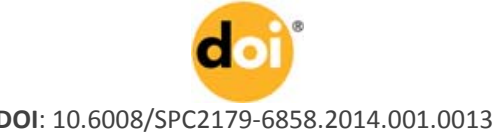

Kátia Regina D'Assunção Ramos Instituto Nacional de Gestão dos Recursos Hidricos, Cabo Verde kathia.regyna@gmail.com

Received: 06/03/2014

Approved: 10/04/2014

Reviewed anonymously in the process of blind peer.

\section{Referencing this:}

RAMOS, K. R. D.. Mudanças climáticas e os desafios do setor dos recursos hídricos em Cabo Verde. Revista Ibero-Americana de Ciências Ambientais, Aquidabã

v. 5, n.1, p.180-197, 2014. DOI: http://dx.doi.org/10.6008/SPC21796858.2014 .001 .0013 


\section{INTRODUÇÃO}

Nos últimos anos, a mudança climática global tornou-se assunto de debate entre as várias esferas da sociedade mundial, regional e local no que diz respeito aos principais problemas ambientais enfrentados no mundo desde a metade do século $X X$. A comunidade científica internacional, leva a público as principais evidências (fiáveis e credíveis) que o aumento da concentração de gases com efeito de estufa (GEE) na atmosfera (comparando com as concentrações do período Pré-industrial), são responsáveis diretos pelo aumento da força radiativa terrestre (antrópica), que consequentemente aquece o Planeta e altera o clima global.

No geral, o chamado "Efeito Estufa" ocorre naturalmente devido a presença de alguns gases na atmosfera. No entanto, a anomalia das concentrações de gases como Gás Carbônico $\left(\mathrm{CO}_{2}\right)$, Metano $\left(\mathrm{CH}_{4}\right)$, Óxido Nitroso $\left(\mathrm{N}_{2} \mathrm{O}\right)$, Hidrofluorcarbonos (HFC), Perfluorcarbonos (CF), Vapor de Água $\left(\mathrm{H}_{2} \mathrm{O}\right)$ e Hexafluoreto de Enxofre $\left(\mathrm{SF}_{6}\right)$, causou um desequilíbrio na composição química da atmosfera, e foram listados no Protocolo de Kyoto como os mais nocivos, pois retém parte da energia solar que a superfície da Terra não absorve, causando um acúmulo de calor na atmosfera (Gráfico 1).

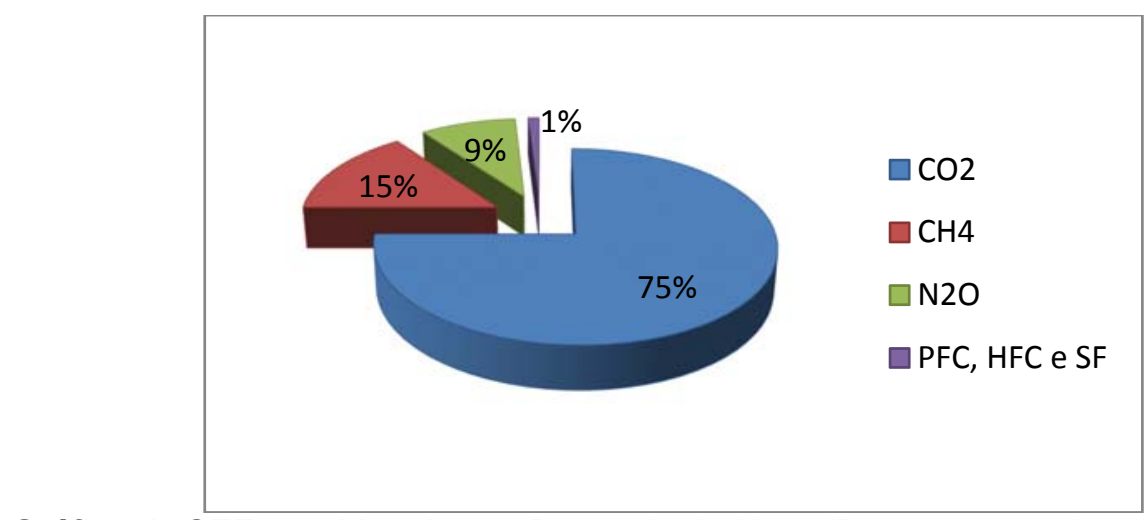

Gráfico 1: GEE considerados no Protocolo de Kyoto(Percentagens de concentração).

Fonte: Adaptado do IPCC, 2007.

O aumento da concentração de GEE, em especial do gás carbônico ou dióxido de carbono, segundo cientistas do National Oceanic and Atmospheric Administration (NOAA), no período pré industrial em 1750 as concentrações de $\mathrm{CO}_{2}$ eram de 280 partes por milhão (ppm), em Maio de 2013 as concentrações atingiram o valor de 400 ppm (Figura 1). Além do aumento da sua concentração o $\mathrm{CO}_{2}$ na atmosfera, há outro fator que o torna mais preocupante, o seu tempo de residência na atmosfera, que pode chegar até 140 anos.

A principal fonte antrópica para o aumento do $\mathrm{CO}_{2}$ na atmosfera da Terra, advém da queima e emissões de combustíveis fósseis (carvão, petróleo e gás) em atividades relacionadas a produção de energia; industrias; mudança no uso do solo; desmatamento e queimadas de florestas, que além de lançar gases na atmosfera, interrompem a transformação de $\mathrm{CO}_{2}$ em oxigênio durante a fotossíntese. 


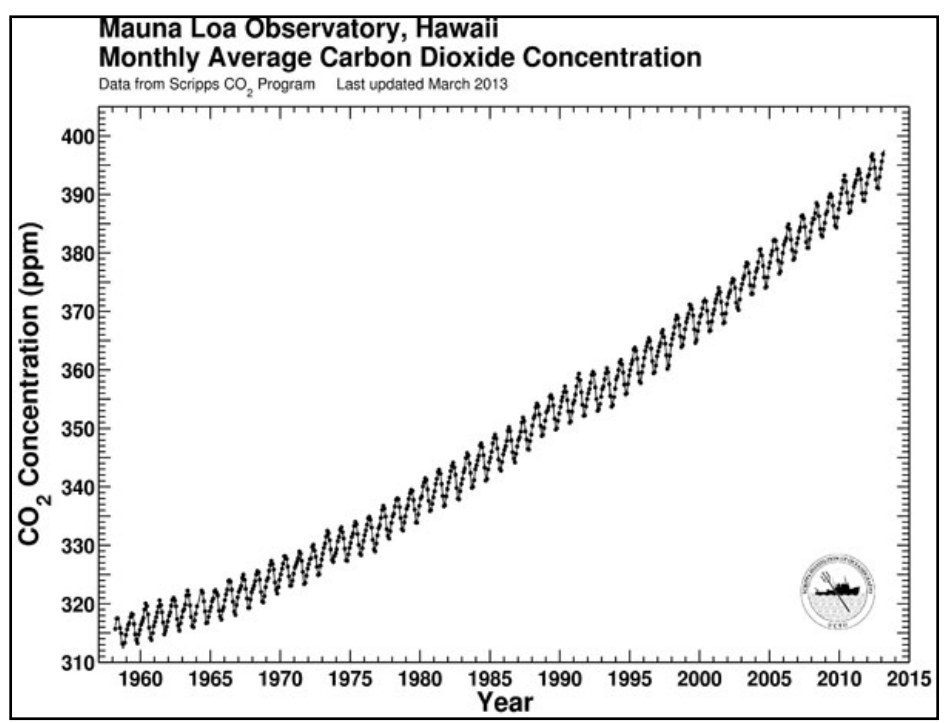

Figura 1: Concentração do $\mathrm{CO}_{2}$ (ppm) de 1960-2013.

Fonte: NOAA, 2013

Depois do $\mathrm{CO}_{2}$ e da água, o metano $\left(\mathrm{CH}_{4}\right)$ é outro gás indutor do efeito estufa de maior importância. Por molécula, um aumento da quantidade de metano no ar causa um efeito de aquecimento 21 vezes maior que a adição de $\mathrm{CO}_{2}$, e reside na atmosfera por cerca de 11 anos. Em média $70 \%$ das emissões atuais de $\mathrm{CH}_{4}$ são derivadas das atividades humanas, sendo produzidas por via biológica pela decomposição anaeróbia de matéria de origem orgânica.

$\mathrm{O}$ óxido nitroso $\left(\mathrm{N}_{2} \mathrm{O}\right)$ é um gás resultante como subproduto de processos de desnitrificação biológica em ambientes aeróbios e de processos de nitrificação biológica em ambientes anaeróbios. A contribuição antrópica, que representa cerca de $40 \%$ das emissões, se dá devido aos processos de degradação que ocorrem em aterros sanitários, a partir de pastagens plantadas em áreas de antigas florestas queimadas, a utilização de fertilizantes a base de amônia e em função da queima de combustíveis que contém nitrogênio, como no caso do carvão e da biomassa.

$O \mathrm{~N}_{2} \mathrm{O}$ chega a ser até 206 vezes mais efetivo que o $\mathrm{CO}_{2}$ em causar o aumento imediato no processo de aquecimento global. De forma similar ao metano, sua concentração atmosférica se manteve constante até cerca de 300 anos atrás, aumentando cerca de $13 \%$ desde o período pré-industrial, sendo a taxa de crescimento anual de cerca de $0,25 \%$. Embora o aumento de $\mathrm{N}_{2} \mathrm{O}$ possa parecer incipiente ao longo do tempo em relação aos demais gases, as concentrações de óxido nitroso é bastante preocupante, uma vez que reside na atmosfera por 80 anos, e o seu fator de aquecimento global chega a ser 114 vezes mais efetivo que o $\mathrm{CO}_{2}$.

Os hidrocfluorcarbono são compostos sintetizados pelo homem para utilização em substituição dos antigos clorofluorcarbonos (CFC), são substâncias bastante persistentes, cuja concentração na atmosfera tem aumentado de forma mais significativa do que qualquer outro GEE (quando contabilizado com os CFCs) nos últimos anos, os hidrofluorcarbonos possuem características de alta eficiência na absorção de determinados tipos de radiação térmica, tendo um potencial de aquecimento global 260 vezes maior que o $\mathrm{CO}_{2}$. 
O hexafluoreto de enxofre (SF) é um composto inorgânico, gasoso e sintético, utilizado pelas mais diversas indústrias, devido às suas características distintas em relação aos demais gases naturais. $\mathrm{O} \mathrm{SF}_{6}$ é um gás bastante estável e de longa vida na atmosfera (70 a 90 anos) Além disso, possui uma grande capacidade de absorção de radiação solar, especialmente nos comprimentos de onda da radiação infravermelha. Sendo assim, o SF 6 é um gás de significativa influência na intensificação do efeito estufa, possuindo um fator de aquecimento global 3.200 vezes superior ao $\mathrm{CO}_{2}$.

Entretanto, as transformações químicas da atmosfera não é um evento novo, uma vez que desde da origem do Planeta a cerca de 4,6 bilhões de anos atrás, houve constantes mudanças que possibilitaram a evolução da atmosfera primitiva, formada provavelmente por metano $\left(\mathrm{CH}_{4}\right)$, amônia $\left(\mathrm{NH}_{3}\right)$, hidrogênio $\left(\mathrm{H}_{2}\right)$ e vapor d'água $\left(\mathrm{H}_{2} \mathrm{O}\right)$, para atmosfera atual conhecida como atmosfera moderna. Essas mudanças estão diretamente relacionada as fortes influências dos fatores físicos-naturais (i.e.), os mecanismos de retroalimentação (feedback), as atividades resultantes da geodinâmica interna da Terra, como as erupções vulcânicas; e atividades resultantes da geodinâmica externa da Terra, como por exemplo os ciclos de Milankovitch, e o fenômeno denominado Mínimo de Maunder caraterizado pelo processo cíclico da diminuição da atividade solar (Teng et al., 2006).

As variações climáticas da temperatura da superfície da Terra são eventos naturais que fazem parte do processo evolutivo do Planeta. Mas, a intensidade e a velocidade como as atuais mudanças estão ocorrendo, são alarmantes numa escala sem precedentes, pelo menos nos últimos 1.400 anos, segundo dados da paleoclimatologia.

No passado geológico o aquecimento e o resfriamento do planeta se deram de forma gradativa no decorrer de milhares de anos, dando tempo para que ao longo de centenas de gerações de plantas e animais os mecanismos do processo evolutivo atuassem (JOLY, 2007).

Segundo Intergovernmental Panel on Climate Change (IPCC - AR5, 2013), há 95\% de certeza que o aumento da concentração de GEE provêm das atividades humanas, e que as contribuições do sistema natural para o aquecimento global é muito incipiente, quase nula.

Os impactos destas alterações, já estão a se manifestar numa escala global, de acordo com IPCC cita-se: Aumento linear de $0,74 \pm 0,18^{\circ} \mathrm{C}$ na temperatura nos últimos 100 anos; Degelo das calotas polares: desde 1978, observou-se que as calotas vem sendo reduzidas a uma taxa de $2,7 \pm 0,6 \%$ por década; Aumento do nível dos oceanos $(3,1 \pm 0,4 \mathrm{~mm} / \mathrm{ano})$ devido ao derretimento das calotas polares e devido à expansão térmica da água; Aumento da frequência de ocorrência de eventos extremos, como tempestades e secas; Aumento da indisponibilidade hídrica.

Atualmente, tornou-se mais frequente relatos na mídia sobre desastres naturais relacionados aos impactos dos eventos hidro meteorológicos extremos. Segundo dados da Rede Global para Redução de Desastres Naturais (ISDR), catástrofes ocasionadas por extremos climáticos, são as que causam maiores perdas no que tange a: vítimas fatais; danos psicológicos e materiais; além de serem as que requerem maiores custos pós tragédia. 
Pequenos Estados Insulares são particularmente vulneráveis às mudanças e a variabilidade climáticas, principalmente no que se refere ao aumento do nível do mar. Como a sua população, terras agrícolas e infraestruturas tendem a concentrar-se nas zonas costeiras, qualquer desequilíbrio no sistema climático tem efeitos significativos e profundos nas suas economias e nas condições de vida.

Devido a isso, em 1990 foi fundada a coligação da Aliança dos Pequenos Estados Insulares (AOSIS), composta por 43 Estados membros, cujo objetivo é o de consolidar as "vozes" dos Pequenos Estados Insulares em desenvolvimento para enfrentar as alterações climáticas globais (AOSIS, 1990).

Entre os Pequenos Estados Insulares em Desenvolvimento (SIDS) e membro da AOSIS vulneráveis a exposição dos eventos climáticos extremos, está a pequena dimensão da República de Cabo Verde (Figura 2), situado entre os paralelos $14^{\circ} 48^{\circ} \mathrm{N}$, e os meridianos $22^{\circ} 44^{\mathrm{W}} \mathrm{W}$, a uma distância aproximadamente de $500 \mathrm{Km}$ da costa ocidental africana, com uma população de 494.401 habitantes e ocupa a terceira maior posição no Índice de Desenvolvimento Humano (IDH) entre países da Comunidade dos Países de Língua Portuguesa (CPLP).

Apesar da sua localização oceânica, o arquipélago de Cabo Verde está inserido na extensão da faixa de aridez do Sahel africano, caracterizado pela longa estação seca durante o ano e irregularidade no regime pluviométrico anual. O País, registra duas estações anuais relacionadas a oscilação da Zona de Convergência Intertropical (ZCIT), sendo a estação seca de Novembro a Junho e a estação húmida (período de chuvas) de Julho a Outubro.

Em geral, o relevo é muito íngreme, culminando com altitudes elevadas (por exemplo, 2,829 m no Fogo e em 1,979m em Santo Antão). As dimensões, configurações e geologia variam muito de uma ilha para a outra, sendo que o País possui uma rede hidrográfica densa e complexa.

No entanto, não existem cursos d'água permanentes e os temporários ocorrerem apenas durante a estação das chuvas. Estes cursos d'água temporários fluem rapidamente para as principais bacias hidrográficas, onde continuam a fluir rapidamente para áreas mais baixas e depois para o mar (PRODOC, 2008).

Devido as características geomorfológicas do arquipélago, há escassez de recursos naturais - nomeadamente, as terras aráveis (menos de 10\%), e a disponibilidade hídrica - têm repercussões não apenas para o desenvolvimento económico e social do país, mas também torna-o ainda mais vulnerável às mudanças climáticas. Se não for acompanhado por medidas de gestão sustentáveis que tenham em conta os riscos e as oportunidades decorrentes das mudanças climáticas, os ganhos significativos conseguidos ao longo das duas últimas décadas em termos de bem-estar e desenvolvimento socioeconómico poderem ser afetados significativamente. Outros aspectos de vulnerabilidade típicos de ecossistemas insulares, como os recursos haliêuticos, os corais e o elevado grau de endemismo entre as espécies terrestres, estão também sob ameaçadas das mudanças climáticas. Os fenômenos extremos climáticos poderão 
trazer consequências nefastas em certos sectores em especial os recursos hídricos, que por sua vez tem impacto sobre a agricultura e a segurança alimentar (PRODOC, 2008).

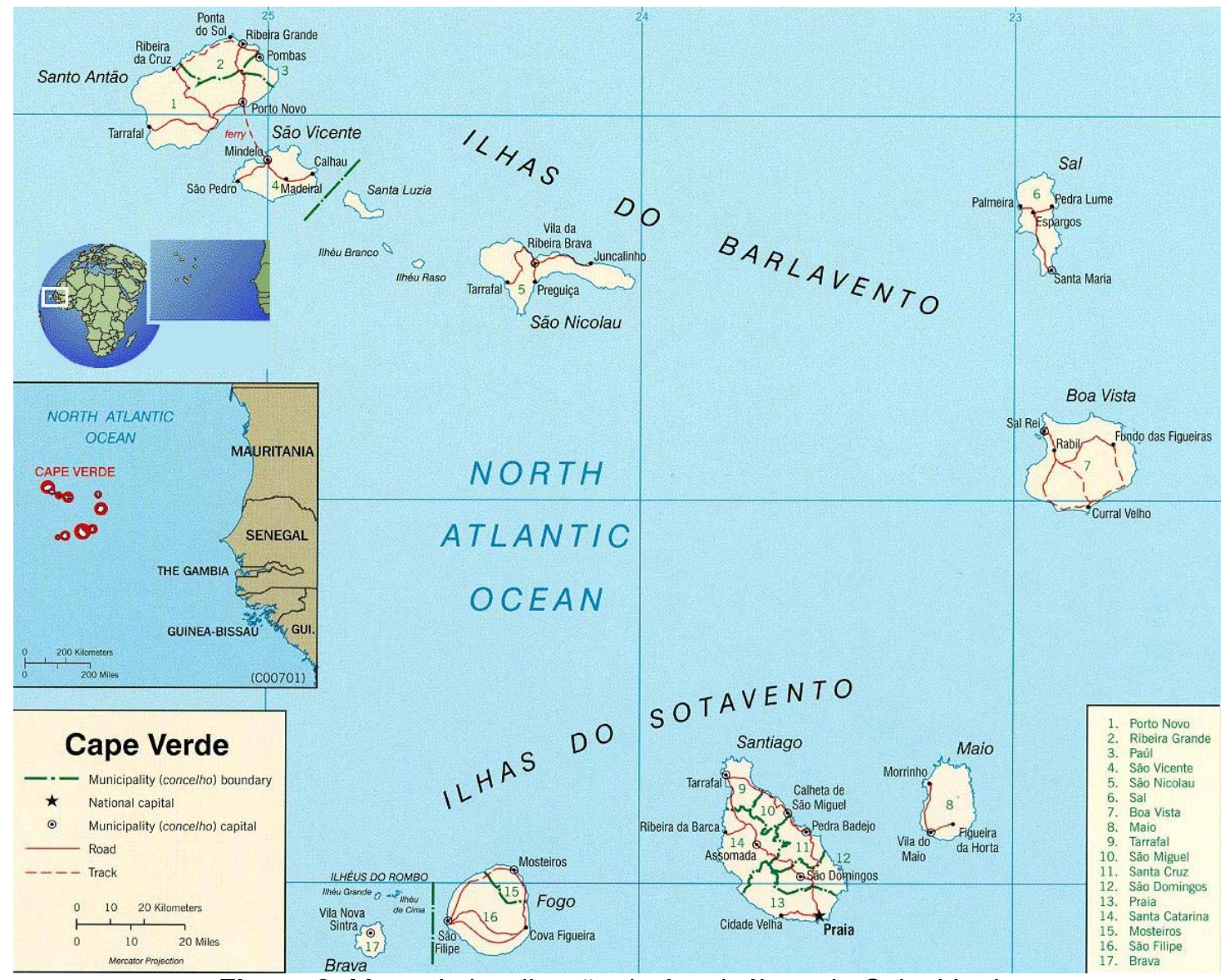

Figura 2: Mapa de localização do Arquipélago de Cabo Verde

A demanda hídrica no País está em constante incremento devido as vulnerabilidades locais. Temperaturas mais elevadas causam maior demanda de água para o consumo e para a agricultura. Desta forma, às mudanças climáticas são outra fonte incremento para demanda da água na região.

Diante do contexto referido, o presente trabalho objetiva avaliar os principais desafios do setor dos recursos hídricos em Cabo Verde frente aos impactos potenciais das mudanças climáticas na região.

\section{METODOLOGIA}

A metodologia do presente estudo, baseou-se em uma abordagem qualitativa quanto aos objetivos do tipo exploratório descritivo. Para a elaboração do estudo realizou-se as seguintes etapas: (i) pesquisa bibliográfica; (ii) construção de um marco conceitual das mudanças climáticas; (iii) elaboração dos elementos de análise; (iv) discussão dos elementos de análise e (v) conclusões. 


\section{DISCUSSÃO}

Cabo Verde integra a lista dos países que vivem em escassez absoluta de água, (i.e.), menos de $500 \mathrm{~m}^{3} / a n o$ de água doce para satisfazer as necessidades da população em termos de agricultura, indústria, energia e meio ambiente. À exceção da água dessanilizada, os recursos hídricos são provenientes do regime pluviométrico e das águas superficiais e subterrâneas.

O balanço hidrológico segundo PAGIRE (2010), estão estimados em 124 milhões de m³/ano dos recursos hídricos subterrâneos. Desse total, a quantidade tecnicamente explorável é estimada em 65 milhões de toneladas por ano, em casos de pluviometria regular, e em 44 milhões de $\mathrm{m}^{3}$ /ano, nos períodos de seca. Quanto os recursos hídricos superficiais estão estimados numa média de 181 milhões de $\mathrm{m}^{3} / \mathrm{ano}$, sendo que, tais recursos são pouco explorados devido à falta de mecanismos eficazes para a captura e armazenamento do bem.

Em termos de infraestruturas referentes a Conservação de Solo e Água (CSA), existem 2.065 poços e furos, 1.196 nascentes, 2.475 reservatório, 862 fontenários e 409 diques de captação (PAGIRE, 2010).

A agricultura de sequeiro e regadio são responsável por cerca de 8 a $9 \%$ do Produto Interno Bruto (PIB) nacional. No entanto, as técnicas de regadio ainda são restritas em virtude das condições agroclimáticas e a cultura de sequeiro detêm $90 \%$ das áreas agrícolas produtivas.

Em meados do ano 2000 iniciou-se uma estratégia nacional do Ministério do Desenvolvimento Rural (MDR) para aumentar a captação de água das chuvas, principalmente para suprir as necessidades do setor agrícola, através do financiamento do Governo da China, no ano 2006 foi construída a primeira barragem de Cabo Verde, a de Polião, localizada na ilha de Santiago, com a capacidade de armazenamento equivalente a $1.700 .000 \mathrm{~m}^{3}$ de água de escorrência, beneficiando cerca de 300 famílias de agricultores.

Em 2013, foram inauguradas mais 4 infraestruturas de captação e armazenamento de água, e está previsto a conclusão de outras 3 barragens até finais de 2014. Tais inciativas partem do financiamento do Governo de Portugal, através da linha de crédito assinado com Governo de Cabo Verde.

Segundo o Governo de Cabo Verde, está prevista a construção de um conjunto de 17 barragens que abarcará todas as ilhas do País, o que possibilitará uma maior captação e armazenamento de água pluvial, beneficiará cerca famílias de agricultores por todo o arquipélago, e irá aumentar as potencialidades nacionais junto ao setor do agronegócio.

Como a disponibilidade de água doce para o consumo, não satisfaz as necessidades da população no País, existem 5 operadores que prestam serviço público no sector da produção da água dessalinizada (maioria opera com técnica de osmose inversa) para o abastecimento às populações e à indústria. A capacidade das operadoras instalada no fornecimento de água, totaliza cerca de $20 \mathrm{mil} \mathrm{m}^{3} / \mathrm{dia}$, o que garante uma disponibilidade na ordem dos 6 a 7 milhões de $\mathrm{m}^{3} / \mathrm{ano}$. 
O tratamento de águas residuais, representa o montante global ascende a cerca de $621.000 \mathrm{~m}^{3} / \mathrm{ano}$, entretanto, esse valor corresponde a menos de $30 \%$ do potencial (PAGIRE, 2010).

Segundo dados do Questionário Unificado de Indicadores Básicos de Bem-Estar (QUIBB, 2007), cerca de $11,5 \%$ da população de Cabo Verde vivem sem acesso a água para o consumo.

A população cabo-verdiana tem acesso limitado à água canalizada, devido ao baixo índice de desenvolvimento em infraestrutura básica, inclusive nos centros urbanos. Como é possível observar no Gráfico 2, a água canalizada através da rede pública serve $51,9 \%$ da população, sendo $62,1 \%$ no meio urbano e $36,8 \%$ no meio rural. O chafariz é utilizado por $30.7 \%$ da população, sendo $27,8 \%$ no meio urbano e $35 \%$ no meio rural. A população abastecida através de auto-tanques representa $6,8 \%$, sendo $8,7 \%$ no espaço urbano e $4 \%$ no espaço rural (QUIBB, 2007).

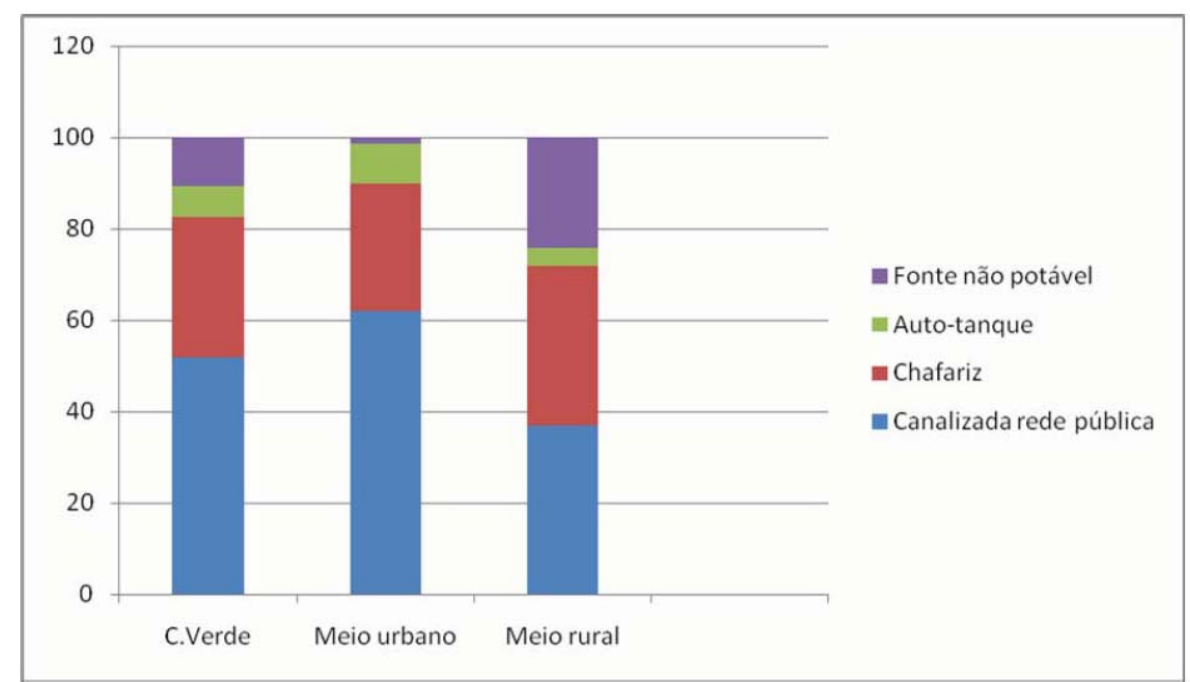

Gráfico 2: Repartição da população cabo-verdiana com acesso a água potável.

Fonte: PAGIRE,2010.

Segundo QUIBB, o abastecimento de água através de uma fonte não potável é feito por $10,5 \%$ da população, sendo $1,4 \%$ no espaço urbano e $24,2 \%$ no espaço rural. Dados do PAGIRE (2010), mostra que o consumo médio de água potável para as populações ligadas a rede é da ordem de 50 litros/habitante/dia, para as ligações domiciliárias e 15 litros/habitante/dia, para os utilizadores dos fontanários, com variação entre 7 e 25 litros. Nessa perspectiva, as necessidades, tendo em conta o quadro atual, para o abastecimento em água potável são estimadas em 18.562 $\mathrm{m}^{3} / \mathrm{dia}$, ou $6.775 .130 \mathrm{~m}^{3} / \mathrm{ano}$, na hipótese baixa e $35.774 \mathrm{~m}^{3} / \mathrm{d}$ ou $13.057 .510 \mathrm{~m}^{3} / \mathrm{ano}$, na hipótese alta. Fatores como a disponibilidade de recursos em águas subterrâneas, a distância entre os pontos de abastecimento de água e os povoados, e o preço da água condicionam o consumo unitário nos fontanários e nas ligações domiciliárias.

Quanto ao controle da qualidade e tratamento da água, são realizados de forma muito irregular, devido principalmente, aos seguintes fatores: i) falta de capacidade técnica; ii) fraca capacidade operativa dos laboratórios; iii) rotura constante do estoque de reagentes; e iv) elevada 
mobilidade de quadros afetos à área. A qualidade da água, no meio rural, não é garantida com regularidade exigida. Em alguns sistemas, a cloração faz-se com relativa frequência, noutros, de tempos a tempos e noutros ainda, pura e simplesmente, não se faz.

O tratamento, quando é feito, resume-se a introdução na água de hipoclorito de cálcio, vulgarmente conhecido por cloro. O que leva a questionar, é se o grau de tratamento é sistemático, eficaz e feito de acordo com as normas nacionais vigentes e as da Organização Mundial da Saúde (OMS).

Outra preocupação, refere-se a falta de mecanismos claros de fiscalização e acompanhamento referente aos parâmetros de qualidade da água. Conclui-se que, uma considerável percentagem da água consumida no País é de qualidade duvidosa. Análises dispersas, realizadas pelo Instituto Nacional de Gestão dos Recursos Hídricos (INGRH), apontam presença de coliformes fecais em muitas amostras e a presença de nitritos e nitratos, que podem ser indicadores de poluição recente ou remota.

Cita-se aqui, evidências da duvidosa qualidade da água consumida: os recentes casos de cólera e o aumento preponderante de doenças diarreicas constituírem uma das causas principais de morbidade e mortalidade geral.

De acordo com o QUIBB (2007), outro aspecto relevante, concerne à evacuação de excrementos humanos, drenagem e tratamento de águas residuais que são precários. Sendo que, somente $59,9 \%$ da população dispõem de um meio seguro de evacuação de excreta, sendo $26 \%$ através de fossa séptica e $33,8 \%$ através de rede de esgotos. Uma parcela considerável da população, principalmente no meio rural, utiliza ao redor da casa e a natureza, para lançarem seus dejetos.

Mesmo com todas as adversidades apresentadas, Cabo Verde está próximo de atingir a meta 7 dos Objetivos do Milénio (ODM) das Nações Unidas - "reduzir para metade, até 2015, a percentagem da população que não tem acesso a água potável de uma forma sustentável, mesmo no meio rural".

Cabo Verde ratificou a Convenção Quadro das Nações Unidas sobre às Mudanças Climáticas (CQNUMC), a 29 de Março de 1995, sendo que a mesma entrou em vigor em 22 de Junho do mesmo ano. Na condição de Parte Contratante da Convenção, o País assumiu nesta data o compromisso de formular a Comunicação Nacional à Conferência das Partes (CDP). Em 2000, apresentou a Primeira Comunicação Nacional (PCN), bem como a sua Estratégia Nacional e o Plano de Ação sobre às Mudanças Climáticas e em 2010, apresentou a Segunda Comunicação Nacional.

Com relação as informações sobre as emissões de GEE, serão apresentadas as que se encontram publicadas na Segunda Comunicação Nacional (SCN) publicada em 2010, tendo como referência o ano de 2000 com a metodologia do IPCC, como ferramenta de cálculo o software produzido pelo Secretariado da United Nations Convention on Climate Change (UNFCCC), que 
segue a decisão da 17/CP.8 para compilação dos inventários dos países não Anexos 1 à Convenção do Clima.

Os GEE cujas emissões e remoções antrópicas que serão apresentados são o $\mathrm{CO}_{2}, \circ \mathrm{CH}_{4}$, o $\mathrm{N}_{2} \mathrm{O}$, os HFCs, os PFCs e o $\mathrm{SF}_{6}$. No entanto, outros gases como o monóxido de carbono (CO), os óxidos de nitrogênio $\left(\mathrm{NO}_{\mathrm{x}}\right)$ e outros compostos orgânicos voláteis não metálicos (NMVOCs), mesmo não sendo GEE diretos, serão aduzidos pois possuem influência nas reações químicas que ocorrem na atmosfera.

Segundo a SCN, no ano de 2000, as emissões antrópicas cabo-verdianas de GEE formam estimadas em 306,80 $\mathrm{CO}_{2}$ (45\% desta emissão provêm da produção de energia e dos transportes); $3,28 \mathrm{Gg} \mathrm{CH}_{4}$ (54\% provém da fermentação entérica); $0,301 \mathrm{Gg} \mathrm{N} 2 \mathrm{O}$ (97\% destas emitidas através dos solos agrícolas) e 0,653 t HFC-134a (por via do consumo de equipamentos de refrigeração). Entre 1995 e 2000 as emissões totais de $\mathrm{CO}_{2}$ aumentaram em 11,7\%, e as emissões totais de $\mathrm{CH}_{4}$ e $\mathrm{N}_{2} \mathrm{O}$ aumentaram em 8,8\% e 12,0\%, respectivamente.

Quanto as emissões antrópicas para os outros GEE com feitos indiretos às mudanças climáticas, formam estimadas para o ano supracitado: $2,03 \mathrm{Gg} \mathrm{NO}_{\mathrm{x}} ; 16,87 \mathrm{Gg} \mathrm{CO}$ e 2,72 $\mathrm{Gg}$ NMVOC. Em termos de $\mathrm{CO}_{2 \text { eq, }}$ com o uso de fator de equivalência Global Warming Potencial (GWP), foi de 21 para o metano de 310 para o óxido nitroso.

Dentro do cenário mundial de emissões de GEE, Cabo Verde tem uma contribuição muito ínfima comparado a outros Países em desenvolvimento médio.

Cabo Verde insere-se nas latitudes abrangidas dentro da zona climática do Sahel, na vizinha África Ocidental, sendo assim, as ilhas experimentam um clima tropical seco com duas estações climáticas distintas: uma estação seca (Novembro a Junho) e uma estação chuvosa (Julho a Outubro), ambas influenciadas por uma combinação de um conjunto de sistemas em larga escala, nomeadamente: Os anticiclones subtropicais dos Açores e de Santa Helena; A Zona de Convergência Intertropical (ZCIT, associada às monções do verão africano); As baixas pressões equatoriais; A corrente marítima das Canárias; A depressão térmica sobre o continente africano durante o Verão; A persistência do "Harmattan" durante a estação seca; A precipitação espaço-temporal aleatória; As flutuações de temperatura; Linhas de instabilidade graves; Episódios frequentes de neblina; As correntes de Jato em altitude.

Enquanto o clima das ilhas compartilha uma série de características com o vizinho Sahel, também apresenta características marítimas. Por essa razão o regime de temperatura das ilhas, caracteriza-se por variações de temperatura moderadas, influenciado pelos oceanos ao redor, resultando numa faixa mais estreita de temperaturas médias e absolutas do que nas vizinhas regiões continentais. Além disso, a topografia variada das ilhas resulta em várias zonas microclimáticas.

A estação seca no arquipélago decorre ao longo de um período de cerca de nove meses, de Novembro a Julho, e é marcada por uma ausência quase total de precipitação. O regime de temperatura durante a estação seca é particularmente influenciado pelos fortes ventos marítimos 
que causam altas taxas de evaporação e pela alta radiação solar. Portanto, a temperatura média mensal do ar pode chegar a $26^{\circ} \mathrm{C}$ e, nas zonas costeiras áridas de algumas ilhas, a temperatura máxima absoluta pode ultrapassar $32^{\circ} \mathrm{C}$. Os meses de Agosto e Setembro são geralmente os mais quentes, sendo Dezembro a Fevereiro os mais frios (Figura 3).
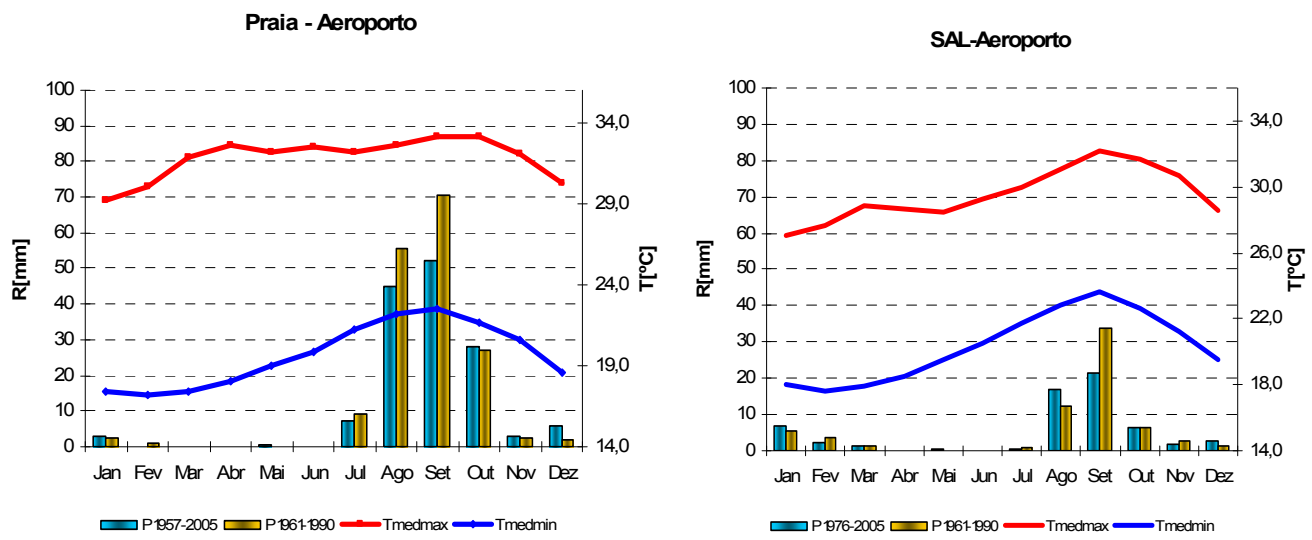

Figura 3: Variação das temperaturas anuais para a cidade de Praia, na ilha de Santiago (montanhosa), e na ilha do Sal (plana). Fonte: CORREIA, 2007.

Como já descrito, as condições climáticas no arquipélago estão relacionados às alterações na zona do Sahel. Portanto, as projeções climáticas produzidas para o Sahel dão indicações das mudanças potenciais que ocorrerão no arquipélago.

As projeções anuais de temperatura e precipitação para o continente africano com base nos dados projetados para o período de 2080-99, em comparação com o período de 1980-1990, estão ilustradas na Figura 4. É possível observar na região Saheliana uma célula de aumento da temperatura projetada que varia de um mínimo de $3^{\circ} \mathrm{C}$ a $4^{\circ} \mathrm{C}$, enquanto, que para as projeções de precipitação para mesma região indicam um decréscimo que varia de 5 a $20 \%$, o que é um fator que põem em risco a sustentabilidade das reservas de água no País.

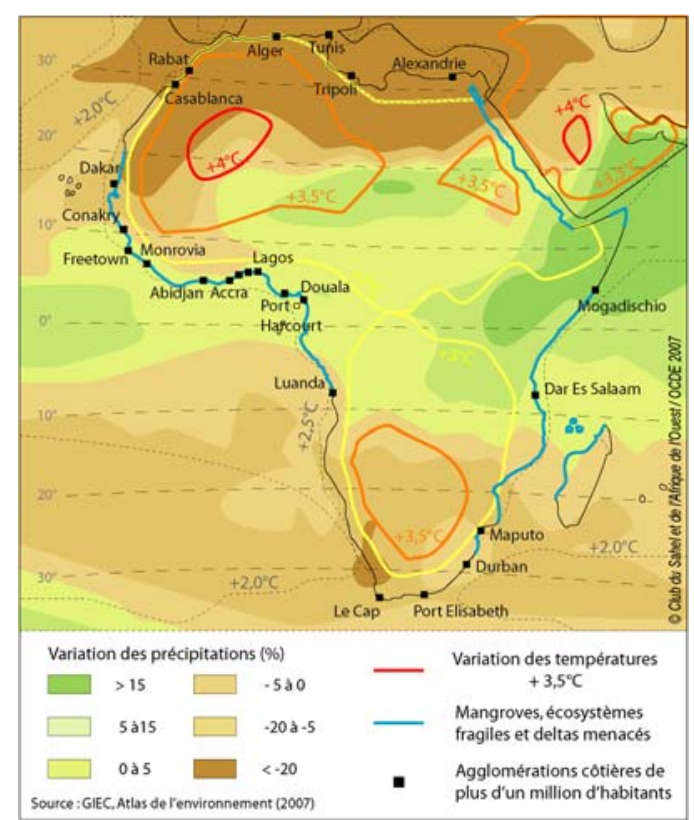

Figura 4: Mapa de projeção da variação da precipitação e temperatura para o Continente Africano.

Fonte: IPCC Atlas do Meio Ambiente, 2007. 
Espera-se que o aquecimento resultante da subida da temperatura aumente igualmente a evaporação potencial, conduzindo a uma redução da umidade do solo se não houver um aumento correspondente na precipitação.

Os modelos de circulação global (GCM) não têm uma resolução precisa o bastante para captar pequenas ilhas, como é o caso de Cabo Verde, portanto as projeções das mudanças climáticas regionais são normalmente baseadas em cálculos sobre a superfície do oceano e não levam em conta as influências físicas da superfície terrestre das llhas (CHRISTENSEN et al., 2007). Por outro lado, os modelos climáticos apresentam erros significativos em simular a posição da Zona de Convergência Intertropical (CHRISTENSEN et al., 2007), causando erros sistemáticos e significativos na precipitação simulada na região e aumento da incerteza associada às mudanças climáticas projetadas.

Segundo projeções do IPCC (AR5, 2013), há um indicativo para um aumento na temperatura do ar à superfície do $2,5^{\circ}$ a $3^{\circ} \mathrm{C}$ para além do já se verifica atualmente, na região oriental tropical atlântica onde Cabo Verde se encontra, ao longo do século. Nota-se que estes valores de aumento são significativamente menores do que aqueles que verificarão nas regiões vizinhas da África Ocidental, devido à influência do arrefecimento do oceano circundante. No entanto, os eventos extremos de temperatura terão tendência a ser cada vez mais frequente e com maior intensidade.

No que concerne a elevação do nível médio do mar, as projeções apontam que até o fim do século 21, é muito provável que o nível do mar aumente em 95\% das áreas oceânicas. Por volta de $70 \%$ das costas por todo o mundo devem sofrer alteração no nível do mar. Conforme ilustrado na Figura 5, o aumento do nível do mar para o período de 2081 a 2100 irá provavelmente variar entre $28 \mathrm{~cm}$ (no cenário otimista RCP 2.6) a $98 \mathrm{~cm}$ (no cenário pessimista RCP 8.5).

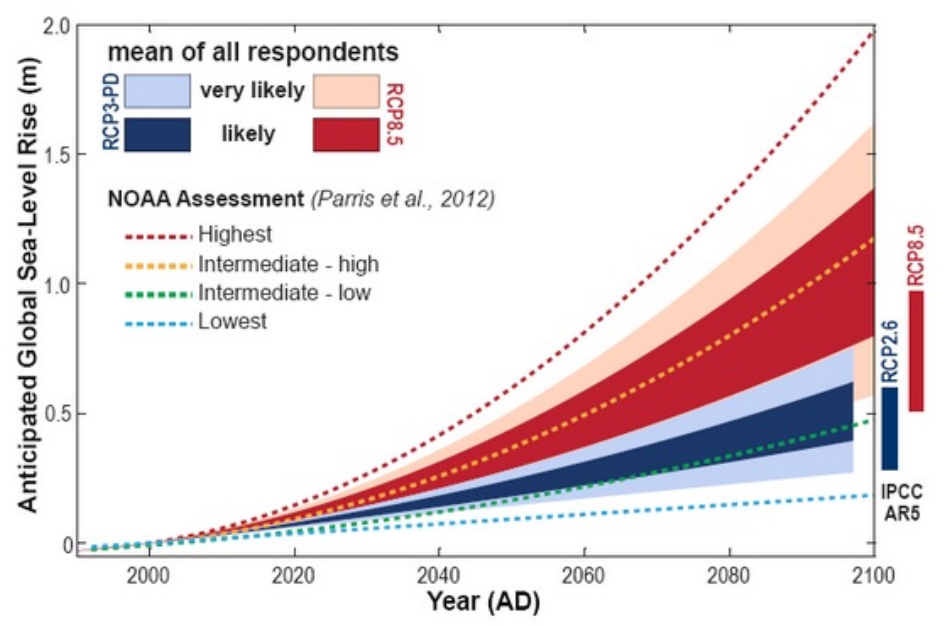

Figura 5: Projeções para aumento do nível médio do mar ao longo do período 2000-2100 para dois cenários de aquecimento global. Fonte: Parris et al. (2012).

Estes dados, indicam uma subida semelhante para a região do Atlântico Oriental Tropical, onde Cabo Verde está situado. Dada a natureza das ilhas e as características do seu litoral, as 
principais vulnerabilidades e riscos deste aumento para Cabo Verde serão o perigo de erosão costeira e da intrusão da cunha marinha nas reservas subterrâneas de água que afectará a disponibilidade hídricas.

Dados do Instituto Nacional de Meteorologia e Geofísica (INMG) houve uma significativa redução das chuvas nos últimos trinta anos. Esta tendência pode vir a piorar devido as mudanças climáticas, resultando geralmente em diminuição da disponibilidade da água doce (PRODOC, 2008).

\section{Impactos da Mudança Climática nos Recursos Hídricos}

Segundo cientistas ligados as questões do clima, às mudanças climáticas alterarão o ciclo hidrológico de forma a resultar em impactos significativos na quantidade e na qualidade dos recursos hídricos em escala global. Enquanto as projetações apontam para um aumento na precipitação em algumas regiões, outras enfrentarão uma tensão hídrica, devido a brusca redução no volume de precipitação.

Bates et al. (2008) destacam que vários estudos divulgados referentes à relação mudanças climáticas e recursos hídricos apresentam três resultados. Em algumas regiões do planeta vem sendo evidenciados aumentos significativos no escoamento superficial, a exemplo das altas latitudes e boa parte dos Estados Unidos. Em regiões localizadas na África Ocidental, sul da Europa e parte da América do Sul vem sendo focalizadas diminuições no escoamento superficial. Há também áreas que não são identificadas tendências negativas e nem positivas no escoamento superficial.

Tingem et al. (2008), analisaram os efeitos dos eventos extremos climáticos sobre a produção agrícola do milho em Camarões, país da África Subsaariana. De acordo com o estudo, a cada evento extremo, seja caracterizado pelo aumento das chuvas e/ou principalmente pela ausência considerável desta, há uma perda na produtividade do milho e acarretando grandes impactos sociais. Verificou-se também, que nos últimos anos as ocorrências destes eventos extremos tornaram-se cada vez mais frequentes, fator que deve ser levado em consideração para as futuras políticas que envolvam a distribuição dos recursos hídricos no país, principalmente a água destinada para irrigação.

De acordo com dados do IPCC, os impactos das mudanças climáticas nos recursos hídricos relacionam-se à:

Mudança nos padrões de precipitação - A evaporação vai aumentar com o aquecimento porque uma atmosfera mais quente pode manter mais umidade e temperaturas mais altas aumentam o índice de evaporação.

Mudanças na frequência e na intensidade da precipitação - Também esperase que, além das mudanças na média global de precipitação, haja mudanças mais intensas nas características das precipitações regionais e locais devido ao aquecimento global. Na média, a tendência da precipitação é ser menos frequente, porém mais intensa, implicando maior incidência de enchentes, inundações e secas extremas. 
Mudanças na média anual de redução do escoamento - Às mudanças na redução do escoamento vão depender das mudanças na temperatura e na precipitação, entre outras variáveis. A maioria dos estudos de modelos hidrológicos concluiu que, embora haja um aumento global da precipitação, existem áreas significativas onde acontecem maiores reduções de escoamento por causa das temperaturas mais altas, o que leva a maiores perdas por evapotranspiração. Assim, a mensagem de aumento da precipitação claramente não se traduz de forma imediata em aumentos regionais na disponibilidade de água de superfície e subterrânea.

Impactos da elevação do nível do mar em zonas litorâneas - Alguns dos principais impactos da elevação do nível do mar em áreas litorâneas incluem (i) inundação de terrenos baixos e deslocamento de áreas úmidas, (ii) tempestade de marés, (iii) mudanças nos padrões de sedimentação, (iv) tempestades mais severas, causando enchentes (v) aumento da intrusão de água salgada lençois freáticos e (vi) aumento de danos causados por ventos e chuvas em regiões dadas a ciclones tropicais.

Mudanças na qualidade da água - As chuvas mais intensas geralmente resultam em maior aumento de escoamento e, em consequência, em um aumento da concentração de sólidos suspensos (turbidez) em cursos de água. Se esse escoamento é acompanhado pelo transporte de poluentes (por exemplo, fertilizantes, pesticidas), que poderá comprometer seriamente a qualidade da água (subterrânea e superficial).

Nota-se, que nos levantamentos supracitados observar-se que os efeitos abruptos das mudanças climáticas atuais já desencadeiam problemas na disponibilidade de água para as atividades humanas. Isso que poderá se agravar caso as alterações climáticas continue nesse ritmo e não sejam formuladas políticas públicas voltadas para um planejamento eficaz dos usos múltiplos dos recursos hídricos.

\section{Cabo Verde e os Desafios dos Recursos Hídricos}

De acordo com um relatório do IPCC sobre o estado dos recursos hídricos em África, apontam que até 2025, a disponibilidade de água em nove países, principalmente na África Oriental e Austral, deverá ser inferior a $1.000 \mathrm{~m}^{3} /$ pessoa/ano. Doze países serão limitados a 1,000-1,700 m³/pessoa/ano, e a população que vive sob de estresse hídrico poderá atingir 460 milhões de pessoas, principalmente na África Ocidental (UNEP/GRID-Arendal, 2002). Tais estimativas são baseadas em taxas de crescimento populacional, e não levam em consideração a variação de recursos hídricos devido às mudanças climáticas. Além disso, uma estimativa realizada, mostra a proporção da população africana em risco de estresse hídrico e crescente escassez de água era de 47\% em 2000 atingirá 65\% em 2025 (Ashton, 2002). Diante disso, poderá aumentar os conflitos sobre a água, principalmente em regiões áridas e semiáridas.

As reservas de água subterrânea são particularmente vulneráveis aos efeitos esperados da mudança climática, relativamente no que toca a redução de chuvas e escoamento superficial, uma vez que essas reservas são recarregadas por infiltração direta das camadas superficiais. Estima-se que até $40 \%$ dos poços, furos e reservatórios estão atualmente sobre explorados. Como já elucidado anteriormente, os recursos disponíveis de água subterrânea atingem 124 
milhões de $\mathrm{m}^{3}$ /ano, com uma média de 65 milhões $\mathrm{m}^{3} / a n o$ tecnicamente explorável e 44 milhões de $\mathrm{m}^{3} / a n o$ em períodos de seca. Está também previsto que estes valores possam diminuir em $25 \%$ nos próximos 20 anos devido às mudanças climáticas.

A demanda crescente por acesso aos recursos hídricos no País está condicionado ao levar em conta os dados apresentados no PAGIRE face a demanda da água (recursos subterrâneos) da população até 2020 como é possível observar no Quadro 1.

Quadro 1. Recursos subterrâneos per capita ( $\left.\mathrm{m}^{3} / \mathrm{ano} / \mathrm{hab}\right)$.

\begin{tabular}{|c|c|c|c|c|}
\hline Regime chuvoso & $\mathbf{2 0 1 0}$ & $\mathbf{2 0 1 5}$ & $\mathbf{2 0 2 0}$ & $\begin{array}{c}\text { Disponibilidade } \\
\text { de água subterrânea }\end{array}$ \\
\hline Ano Chuvoso & 236 & 215 & 196 & 124 \\
\hline Ano Médio & 124 & 112 & 103 & 65 \\
\hline Ano Seco & 84 & 76 & 70 & 44 \\
\hline População Projetada & 525,310 & 577,926 & 743,317 & \\
\hline
\end{tabular}

Fonte: PAGIRE, 2010

Ao utilizar o coeficiente de escoamento de $20-53 \%$ da pluviometria, encontrados por diferentes estudos desenvolvidos para quantificar os recursos superficiais, e o coeficiente de infiltração de 13-17\%, a disponibilidade média por habitante em águas subterrâneas tecnicamente exploráveis utilizando estes parâmetros como apresentado no quadro anterior, deixa explícito que é impossível satisfazer as necessidades da população, somente com recurso à água subterrânea. Observa-se também, que Cabo Verde sofre de uma escassez crônica de recursos hídricos estimada em cerca de $1000 \mathrm{~m}^{3} / \mathrm{hab} x$ ano (FERREIRA, 2013).

A população em crescimento e emergente de Cabo Verde e a expansão do sector do turismo contribui para o aumento da demanda hídrica, com forte reflexos no aumento também da demanda no setor industrial, que juntos estão estimados em $5.500 \mathrm{~m} 3 /$ dia. A disponibilidade de água é muito importante para o crescimento do sector turístico, que é preponderante ao desenvolvimento económico do País. Segundo dados do INE, o número de turistas para Cabo Verde está projetado ascender de 250.000 para 3,6 milhões até 2017. Este aumento, poderá contribuir significativamente ao desenvolvimento económico. No entanto, não é clarificado nos instrumentos de planejamento como o sector da água irá responder a ascensão da demanda hídrica.

Sob o prisma do setor dos recursos hídricos e do setor do turismo no País, as estratégias atuais de ambos setores não estão num mesmo diapasão. Apesar disso, estima-se que aumente o número de visitantes a Cabo Verde nos próximos 10 anos. Isso irá exacerbar consideravelmente a falta de água colocando e acrescentando desafios para uma gestão sólida e integrada dos recursos hídricos. Uma acentuada falta de água certamente, afetará o crescimento do turismo regional no futuro próximo.

As grandes infraestruturas para captação e armazenamento de água para a agricultura, são medidas que poderão auxiliar na sustentabilidade do setor da agricultura face às mudanças climáticas. No entanto, esses grandes investimentos, não levaram em consideração os potenciais perigos hidro meteorológicos das mudanças climáticas. Para o cenário de chuvas do tipo 
torrenciais, elevará o risco recairá de assoreamento a de sedimentação das barragens, o que diminuirá a capacidade de retenção das águas de escoamento superficial. Já para o cenário de elevação da temperatura do ar à superfície e casos de secas extremas, elevarão os riscos do aumento da evaporação da água captada e da diminuição da recarga anual devido aos baixos índices pluviométricos.

Salienta-se que na perspectiva do gênero, é muito comum, principalmente no meio rural, que as mulheres e meninas sejam as responsáveis em assegurar o transporte de água do ponto de abastecimento à residência, muitas vezes, com percursos de 4 a 6 horas, deslocando-se à fonte em média, 2 a 3 vezes ao dia. A água é transportada à cabeça, em precárias condições higiénicas, em vasilhames de 20 ou mais litros, podendo prejudicar, seriamente, a postura das pessoas, sobretudo as crianças que são submetidas a esse esforço. A vulnerabilidade das mulheres e das meninas tende a aumentar frente às mudanças climáticas, pois cabem a elas o papel da busca e da gestão dos recursos hídricos, que cada vez mais se tornará limitado.

\section{CONCLUSÕES}

A gestão sustentável dos recursos hídricos em Cabo Verde é um assunto complexo, e os desafios são múltiplos. Não se pode analisar às mudanças climáticas de uma forma isolada e separada dos desafios gerais de desenvolvimento do País. Do mesmo modo, as causas de base da fraca capacidade de adaptativa ou alta vulnerabilidade frente às mudanças climáticas são originadas tanto por fatores climáticos como os não climáticos. Apesar desses desafios conceituais as causas mais importantes e dominantes a considerar são as seguintes:

- Apesar da água ser escassa e crítica a sua gestão ainda é incipiente. A água é desperdiçada tanto na agricultura, como no consumo humano nas zonas urbanas e rurais e muitas fontes de água encontram em sobre-exploração. Técnicas simples, mas louváveis, poderiam reduzir o desperdício de água, nomeadamente o seguimento regular dos poços e furos e a melhoria da manutenção das tubagens de adução e distribuição.

- Também, técnicas relativamente simples que foram utilizadas no passado e que mostraram melhorar a disponibilidade de água em vários lugares, hoje já não são tão praticadas, como: a reflorestação e proteção de bacias hidrográficas, retenção da água e técnicas para captação da água de nevoeiro no cume das ilhas mais montanhosas. Embora tenham mostrado que melhoram a disponibilidade da água, não são exploradas em larga escala.

- Os investimentos em infraestruturas e sua manutenção são insuficientes para maximizar o uso das águas superficiais e subterrâneas, e a água com frequência não chega a localidades mais remotas.

- As políticas nacionais e locais no geral não integram dentro das suas estratégicas para médio e longo prazo as perceptivas das mudanças climáticas. Medidas adaptativas proativas e 
deliberadas podem garantir a sustentabilidade dos recursos hídricos aos seus diversos usos mesmo frente a perigos iminentes do clima.

- As informações sobre às mudanças climáticas não são ainda suficientemente disseminadas. Planificadores, decisores, gestores públicos sociedade civil e comunidades não possuem informações continuas sobre o assunto, o que ocorre são informações mediadas de forma pontual e de maneira insuficiente.

\section{REFERÊNCIAS}

AERTS, J.; DROOGERS, P.. Adapting to climate change in the water sector. In: LUDWIG, F.; KABAT, P.; VAN SCHAIK H.; VAN DER VALK M.. Climate Change Adaptation In The Water Sector. Earthscan: London, 2009. p.87-108

BATES, B.; ZBIGNIEW, W. K.; WU, S.; PALUTIKOF, J.. El cambio climático y el agua. Secretaría del IPCC: Ginebra, 2008.

BATES, B. C.; KUNDZEWICZ, Z. W.; WU, S.; PALUTIKOF, J. P.. Climate Change and Water: technical paper of the Intergovernmental Panel on Climate Change. IPCC Secretariat: Geneva: 2008.

CHRISTENSEN, J. H.; HEWITSON, B.; BUSUIOC, A.; CHEN, A.; GAO, X.; HELD, I.; JONES, R.; KOLLI, R. K.; KWON, W-T, LAPRISE, R.; MAGAÑA RUEDA, V.; MEARNS, L.; MENÉNDEZ, C. G.; RÄISÄNEN, J.; RINKE, A.; SARR, A.; AND WHETTON, P.. Regional Climate Projections. In: Climate Change: the Physical Science Basis. Cambridge, 2007.

FERREIRA, T. C.. Caracterização climática: vulnerabilidade e potenciais medidas de adaptação em Cabo Verde. Cabo Verde, 2013.

INGRH. PAGIRE: Plano Ação de Gestão dos Recursos Hídricos. 2010.

IPCC. Climate Change 2001: Impacts, Adaptation and Vulnerability. Cambridge University Press, Cambridge, p.877-912, 2001.

IPCC. Working Group I contribution to the IPCC fifth assessment report (ar5), climate change 2013: the physical science basis. Stockholm, 2013.

JOLY, C. A. Biodiversidade e mudanças climáticas: contexto evolutivo, histórico e político. In: CONGRESSO DE ECOLOGIA DO BRASIL, 8. Anais. Caxambu, 2007.

MCSWEENEY, C.; NEW, M.; LIZCANO, G.. O UNDP Perfis do País às Mudança Climática UNDP. Cabo Verde, 2008.

Ministry of Environment and Agriculture. National Report on Cape Verde. GEF UNDP ACCC Project, 2006.

Ministry of Environment and Agriculture. National Adaptation Programme of Action on Climate Change. 2007.

PRODOC. PNUD GEF PIMS nº. 4091: reforço das capacidades de adaptação e resiliência às Mudanças Climáticas no Sector dos Recursos Hídricos em Cabo Verde. 2008.

RAHMSTORF, S.. A semi-empirical approach to projecting future sea-level rise. Science, n.315, p.368370, 2007.

REDELSPERGER, J. L.; JANICOT, S.; DIEDHIOU, A.. West African Monsoon Project. In: CONFERENCE ON HURRICANES AND TROPICAL METEOROLOGY, 25. Anais. p.275-276. Californie: AMS, 2002.

REPUBLIC OF CAPE VERDE. Second National Communication on Climate Change of Cape Verde. United Nations Framework Convention for Climate Change: 2010. 
SINGH, B.. Análise e seguimento de dados sobre Mudanças Climáticas. Cabo Verde, 2012.

TENG, H.; WASHINGTON, W. M.; MEEHL G. A.; BUJA, L. E.; STRAND, G. W.. Twenty-first century Arctic climate change in the CCSM3 IPCC scenario simulations. 2006.

TINGEM, M.; RIVINGTON, M.; COLLS, J.. Climate variability and maize production in Cameroon: Simulating the effects of extreme dry and wet years. Singapore Journal of Tropical Geography, n.29, p.357-370, 2008.

UNEP. Global sea-level rise. UNEP/GRID-Arendal Maps and Graphics Library. 2009

UNEP. Towards a green economy: investing in energy and resource efficiency. United Nations Environment Programme, 2011.

UNFCCC. United Nations Framework Convention on Climate Change. Climate Change: impacts, vulnerabilities and adaptation in developing countries. 2007. 